\title{
Emerging environmental engineering in Brazil
}

\section{R. S. Darby, Member}

Having returned earlier this month from a British Executive Services Overseas (BESO) project, concerned primarily with the collection and disposal of municipal wastes in the city of Tarija in Bolivia, I should like to make a written contribution related to the content of the above paper. I have also worked for some years in the chemical industry in Brazil and more recently in evaluating the potential for the generation of electricity from urban wastes in the UK.

88. Tarija has a population of about 120000 people and the collected urban waste amounts to $55 \mathrm{t} /$ day. A licensed landfill site, funded and designed by a Japanese company, takes the waste. The Bolivian authorities have set out reasonable guidelines covering the design of such sites. Due to the isolation of the city there are no customers within a realistic distance for there to be any possibility of recovering and recycling waste, other than returnable glass bottles. The quantity and composition of the waste is such that the recovery of energy values, either from the landfill gas or from an incineration plant, is not viable. There is merit in investigating means of extending the collection of waste to cover the whole city, and also to progress the production of compost.

89. For much of South America the issues arising from the collection and disposal of municipal wastes have to be seen in the context of the local culture as well as identifying the environmental impacts and the associated engineering and management solutions. On average, the quantities of domestic waste produced per individual in South America are considerably less than in the UK, though much waste is not officially collected. The environmental effects of the latter arguably makes the efficient collection of all urban waste one of the more significant issues needing resolution, particularly as it invariably involves the poorer sections of the community. The production of compost in these poorer areas deserves more attention as a solution to both collection and disposal, and also as a means of involving local communities. This is happening in Salvador in Bahia, Brazil, and was recommended for Tarija.

90. A major contributory factor to the reduced quantities of waste produced is that less paper and board are used and this is reflected in the composition of the waste. A typical percentage for paper/board in the UK is
$33 \%$, while in South America is can be as low as $6 \%$. Not only are density and potential compaction affected by the composition, but the calorific value of South American waste can be significantly less than in the UK. Clearly, this has an adverse influence on the viability of incineration with associated recovery of energy values.

91. During the past ten years the UK Government has pursued a successful policy of financially encouraging the recovery of energy values from waste and more recently taxing landfill to encourage alternative disposal routes. The energy utilization of landfill gas deserves mention as this has already been applied in Santiago in Chile and should find other applications in South America. However, during my recent stay in Tarija and immediately before that in Salvador, it became clear that South American engineers are usually aware of the new waste technologies, but neither they nor their colleagues from abroad always appreciate the implications of different financial and regulatory regimes on the development and viability of these systems, or for that matter the differences in the characteristics of the municipal waste raw material.

92. Engineers hoping to participate in the work needed to find and implement environmentally safe solutions to the collection and disposal of municipal waste in Brazil or most other countries in South America, should be made aware of the differences previously mentioned. It is suggested that these differences are of a more fundamental nature than those which may arise in the other sectors identifiedeffluent treatment (sanitation), air pollution control and waste minimization.

\section{Author's reply}

There have been some recent operational and policy changes developing in Brazil regarding the collection and treatment of municipal wastes and this has mainly occurred in the city of São Paulo, now a megalopolis of an estimated 17 million inhabitants.

94. Some 26 years ago the city authorities set up a municipal refuse collection and compost generation facility located on 15000 square metres of property on what was then the outskirts of São Paulo. There are now two of these facilities functioning in the city. The first plant treats $1000 \mathrm{t} /$ day collected from three neighbouring suburbs in a continuous opera-
Paper published: Proc. Instn Civ. Engrs Mun. Engr, 1999, 133, June, 83-92 
tion. From the collected wastes, slightly over $50 \%$ becomes organic matter (compost) and is sold for $\mathrm{R} \$ 0 \cdot 50$ (equivalent to $\operatorname{US} \$ 0 \cdot 25$ ) per ton for agricultural application. Up until about five years ago, total composting took place.

However, because the facility became surrounded by industries and other urban expansion, complaints to the environmental authorities regarding odour emissions resulted in reducing the decomposition by $50 \%$. This meant that the end-users had to complete the process on their own properties.

95. From the remaining residue about $5 \%$ is manually extracted, consisting of glass, plastics, aluminium, cardboard, etc. which is picked up by recycling entities. The rest, which is relatively solid, is transported to licensed landfill sites.

96. Following substantial studies by the municipal authorities it was decided to semiprivatize this operation and, following invitations, two private companies (one being French) were granted concessions to operate the waste collection and composting operations using the locally established technology. It is now proposed to call for proposals for the establishing and operating of nine similar facilities to be located strategically throughout the city.

97. The technology that has been developed over the past two decades by the São Paulo municipal authorities has shown that the operation is very simple, requires low capital investment and has become so efficient that they have decided to close down the two existing large incinerator facilities.

98. With regard to recycling, this has suddenly become an incredible 'happening' in Brazil, particularly regarding collection, where thousands of unemployed poor people have developed into an 'industry' where daily collection of recyclable materials (aluminium, paper, cardboard and plastics, etc.) is being carried out in an informal manner by literally an antlike army of people who have become responsible for the collection of over $90 \%$ of these recyclable materials. Brazilian federal authorities believe that the country now has the highest percentage of recovered aluminium waste in the world.

99. Municipalities throughout Brazil are now beginning to adopt this system for the collection and treatment of domestic urban waste and several Central and South American countries are beginning to visit the São Paulo facility with a view to assimilating and adopting a similar policy in their own countries.

100. This all means that there will no longer be a trend towards incineration for the treatment of urban wastes in Brazil. Co-generation will, however, be a continued source of energy in this country but the raw materials will probably be sourced more from bagasse (Brazil being the world's greatest producer of sugar cane), sawdust (from the lumber-producing states), and man-made tree plantations utilizing short rotation coppice and forestry residues. 